\title{
Catalytic dehydrogenative coupling of hydrosilanes with alcohols for the production of hydrogen on-demand: Application of the pair silane/alcohol as liquid organic hydrogen carrier
}

\author{
David Ventura-Espinosa, ${ }^{[a]}$ Alba Carretero-Cerdán, ${ }^{[a]}$ Miguel Baya ${ }^{[b]}$ Hermenegildo García, ${ }^{*[c]}$ and Jose
}

A. Mata*[a]

\begin{abstract}
The $\left[\mathrm{Ru}(p-\mathrm{cym})(\mathrm{Cl})_{2}(\mathrm{NHC})\right]$ is an effective catalyst for the room-temperature coupling of silanes and alcohols with the concomitant formation of molecular hydrogen. High catalyst activity is observed for a variety of substrates affording quantitative yields in minutes at room temperature and with a catalyst loading as low as 0.1 mol \%. The coupling reaction is thermodynamically and, in the presence of Ru complex, kinetically favourable and allows rapid molecular hydrogen generation on-demand at room temperature, under air, and without any additive. The pair silane/alcohol is a potential liquid organic hydrogen carrier (LOHC) for energy storage over long periods in a safe and secure way. Silanes and alcohols are non-toxic compounds and do not require special handling precautions such as high pressure or inert atmosphere. These properties enhance the practical applications of the pair silane/alcohol as a good LOHC in the automotive industry. The variety and availability of silanes and alcohols permits a pair combination that fulfils the requirements for developing an efficient LOHC.
\end{abstract}

\section{Introduction}

Energy production based on carbon fossil fuels has direct negative implications in the climate change due to the formation of $\mathrm{CO}_{2}{ }^{[1]}$ To tackle this problem, wind and solar based energies are emerging as potential alternatives for energy production. ${ }^{[2,3]}$ However, one of their major limitations is the intermittent character, which in addition relies on meteorological factors. Herein, the success of renewable energies is ligated to the efficient development of energy storage systems that would allow the production of energy on-demand. ${ }^{[4-6]}$ In this regard, the energy storage in the form of chemical bonds is very promising. ${ }^{[7]}$ In particular, the "hydrogen economy" is based on the use of $\mathrm{H}_{2}$ as energy vector. This gas can be used on-demand as fuel when combined with $\mathrm{O}_{2}$ (even from air). The system has a high energy density and the only generated byproduct is water ${ }^{[8-10]}$ The

[a] D. Ventura-Espinosa, A. Carretero-Cerdán and Dr. J. A. Mata Institute of Advanced Materials (INAM), Universitat Jaume I. Avda. Sos Baynat s/n, 12006, Castellón (Spain) e-mail: jmata@uji.es

[b] Dr. M. Baya

Instituto de Síntesis Química y Catálisis Homogénea (ISQCH), Departamento de Química Inorgánica, CSIC-Universidad de Zaragoza, C/Pedro Cerbuna 12, E-50009 Zaragoza (Spain)

[c] Prof. H. García.

Instituto de Tecnología Química (ITQ), Universidad Politécnica de Valencia. Avda. Los Naranjos s/n, 46022, Valencia (Spain) e-mail: hgarcia@qim.upv.es

Supporting information for this article is given via a link at the end of the document. energy obtained from hydrogen by means of a combustion motor or a fuel cell could easily be adapted to portable energy systems. In an ideal situation, hydrogen should be obtained from the electrolysis of water using wind or solar energy, safely stored and transported and used on-demand. However, the low boiling point, its gaseous nature and the reactivity represents currently a strong limitation to its development. ${ }^{[11,12]}$ Hydrogen storage in the form of liquid organic hydrogen carriers (LOHC) is very promising. ${ }^{[13-15]}$ In the present work, we analyse the catalytic dehydrogenative coupling of hydrosilanes with alcohols as a potential system for hydrogen storage (Figure 1).

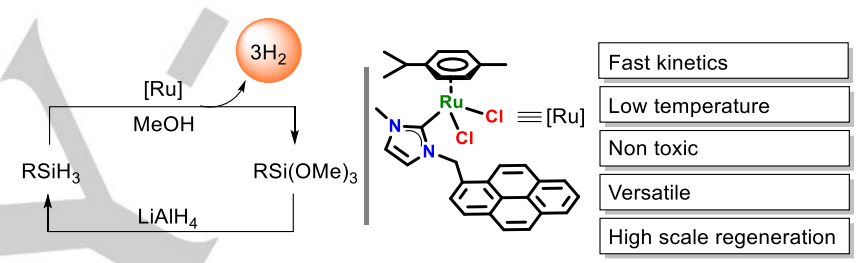

Figure 1. Implementation of silane/alcohol as a liquid organic hydrogen carrie catalysed by ruthenium.

A potential $\mathrm{LOHC}$ requires a fast dehydrogenation reaction to control the production of molecular hydrogen on-demand. ${ }^{[16-19]}$ The dehydrogenation coupling of hydrosilanes and alcohols is a catalytic controlled process. ${ }^{[20-23]}$ As it will be shown here, the ruthenium complex $\left[\mathrm{Ru}(p\right.$-cym $\left.)(\mathrm{Cl})_{2}(\mathrm{NHC})\right]$ is a very efficient catalyst, controls the reaction kinetics and produces hydrogen at high rates. A major drawback found in most LOHCs is the elevated temperatures required in the dehydrogenation process. The coupling reaction of hydrosilanes and alcohols is carried out at low temperatures and proceeds even at $0{ }^{\circ} \mathrm{C}$. The different type of hydrosilanes and alcohols available, make the system a versatile LOHC. The system makes possible the combination of a hydrosilane/alcohol pair with suitable melting and boiling points. The efficient storage of hydrogen in the form of LOHC is a breakthrough technology for the next years. ${ }^{[24-26]}$ Different types of organic substances have been considered as potential LOHCs (Figure 2). Cycloalkanes are good candidates as LOHC due to the high hydrogen capacity. ${ }^{[17,27,28]}$ The main problem of cycloalkanes is the high temperature needed for hydrogen release. $\mathrm{N}$-heterocycles require lower temperatures without decreasing the storage capacity. ${ }^{[29][30]}$ The dehydrogenation of cycloalkanes and $\mathrm{N}$-heterocycles is an endothermic process and requires high temperatures and/or efficient catalysts. In general, molecular hydrogen has to be removed from the reaction media for quantitative conversions. Formic acid is a good LOHC because is abundant and easy to obtain. ${ }^{[31-34]}$ The problem is the production of one mole of $\mathrm{CO}_{2}$ for each mole of molecular hydrogen. ${ }^{[35-37]}$ Ammonia-borane is considered one of the most suitable LOHC. ${ }^{[38-40]}$ The hydrogen storage capacity is high and 
even more important is the number of efficient catalysts developed for the rapid hydrogen release. ${ }^{[41-43]}$ Dehydrogenation of formic acid or ammonia-borane are both thermodynamically driven processes, which means that the reactions can progress under mild conditions using appropriate catalysts. The main inconvenient of ammonia-borane as LOHC is the regeneration process. ${ }^{[44-46]}$ The hydrolysis of ammonia-borane forms stable borates difficult to recover.



Figure 2. Organic compounds used as LOHC. Hydrogen storage capacity (HSC), dehydrogenation reaction and effective hydrogen storage capacity (effHSC).

The potential application of hydrosilanes as LOHC is based on controlling the dehydrogenation process allowing the production of molecular hydrogen on-demand. The formation of molecular hydrogen from the coupling of hydrosilanes and alcohols is a spontaneous thermodynamic process. This is very convenient for an effective control of the reaction conditions including temperature and rate of hydrogen production. ${ }^{[47]}$ The reverse process, i.e. the regeneration of the silyl ether, is a nonspontaneous reaction. These reactions normally require severe conditions, such as high temperatures and/or pressures, producing more waste and contaminants. From an environmental point, reactions that produce hazardous substances should be avoided or if not, should be carried out in industrial facilities where contaminants and by-products are controlled. The production of waste can be trapped, treated and reused making the global process sustainable. The situation is very different when many individuals produce the same amount of waste without control. In essence, the global process implies obtaining energy on-demand from renewable sources using a sustainable energy vector.
In this work, we have evaluated the coupling reaction of a silane with an alcohol as an efficient $\mathrm{LOHC}$. The reaction can release several moles of hydrogen depending of the hydrosilane. The reaction is spontaneous and requires a catalyst to proceed, which controls the overall process. The enthalpy of the reaction is favoured by the formation of strong $\mathrm{Si}-\mathrm{O}$ bonds and the entropy is favoured by the released of hydrogen gas. This allows the use of low temperatures for hydrogen production on-demand. The reaction is versatile in terms of the different silanes and alcohols that could be coupled, just avoiding the use of solids and gases for practical purposes. The silanes and alcohols are available in bulk quantities, an important issue to consider for developing industrial applications. The coupling product is molecular hydrogen and a silyl ether that could be regenerated to the corresponding hydrosilane or used in the silicone industry. In this manuscript, we describe the results on the dehydrogenative coupling of hydrosilanes and alcohols catalysed by a ruthenium complex. The potential application of the pair silane/alcohol as a LOHC is analysed underlying the advantages and disadvantages from a chemical and technological point of view.

\section{Results and Discussion}

\section{Catalytic studies}

The catalytic dehydrogenative coupling of silanes and alcohols was optimized using dimethyl phenyl silane as model substrate. In a typical experiment, the molecular ruthenium complex is dissolved in the appropriate alcohol. The alcohol is used as reagent and solvent for practical purposes (Table 1). The reaction bath is set at $30^{\circ} \mathrm{C}$ and the hydrosilane is added with a syringe. Immediately, the reaction starts generating hydrogen that was quantified using an inverted burette. The $\left[\mathrm{Ru}(p\right.$-cym $\left.)(\mathrm{Cl})_{2}(\mathrm{NHC})\right]$ complex is air stable and the optimization of the reaction was carried out under aerobic conditions. Using a catalyst loading of 1 $\mathrm{mol} \%$ the reaction is complete in $30 \mathrm{~s}$ with $\mathrm{MeOH}, \mathrm{EtOH}, n \mathrm{PrOH}$ and $n \mathrm{BuOH}$ (Table 1, entries $2-5$ ). We have observed that the reaction is very fast for $\mathrm{MeOH}$ and $\mathrm{EtOH}$, it takes place in less than $1 \mathrm{~min}$, even at a catalyst loading of $0.1 \mathrm{~mol} \%$ (Table 1 , entries 10-11). The reaction is also very fast even at $0^{\circ} \mathrm{C}$ (Table 1 , entry 14). The reaction profile at different temperatures in the range of -25 to $30^{\circ} \mathrm{C}$ shows that quantitative yields are obtained in short times (Vide infra). Fast catalytic dehydrogenation reactions that operate under air and require low temperatures are very promising candidates for efficient LOHCs. The most reactive alcohol is $\mathrm{MeOH}$ that even at low catalyst loadings affords quantitative $\mathrm{H}_{2}$ production yields. The product of the reaction is the corresponding silyl ether isolated and analysed by ${ }^{1} \mathrm{H}$ NMR spectroscopy by simple evaporation of the alcohol. This is a first indication that the system has potential for recovery and recycling.

The $\left[\mathrm{Ru}(p\right.$-cym $\left.)(\mathrm{Cl})_{2}(\mathrm{NHC})\right]$ complex is active in the coupling reaction of a variety of silanes and alcohols (Table 2). Primary, secondary and tertiary silanes are completely dehydrogenated producing three, two and one moles of hydrogen respectively. The silyl ether products are stable under the reaction conditions and are isolated by simple alcohol evaporation. The reactions are also 
efficient at low catalyst loadings in good yields. The low catalyst loadings are especially important if we consider that the reactions are carried out without special precautions, employing regular solvents and reagents used as received from commercial suppliers.

Table 1. Optimization of reaction conditions in the dehydrogenative coupling of silanes and alcohols.

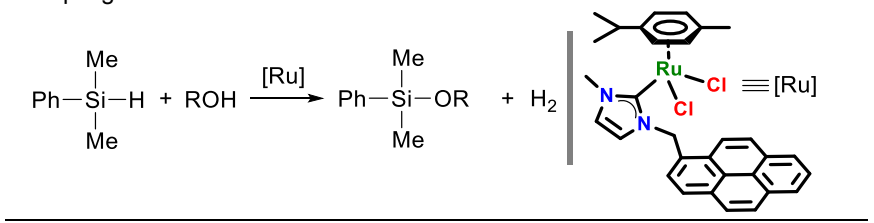

\begin{tabular}{|c|c|c|c|c|c|}
\hline Entry & {$[\mathrm{Ru}](\mathrm{mol} \%)$} & $\mathrm{T}\left({ }^{\circ} \mathrm{C}\right)$ & $\mathrm{ROH}$ & Yield (\%) ${ }^{[a]}$ & $\mathrm{H}_{2}(\mathrm{~mL})^{[\mathrm{b}]}$ \\
\hline 1 & - & 50 & $\mathrm{MeOH}$ & 0 & 0 \\
\hline 2 & 1 & 30 & $\mathrm{MeOH}$ & 100 & 22.2 \\
\hline 3 & 1 & 30 & $\mathrm{EtOH}$ & $100(93)$ & 22.0 \\
\hline 4 & 1 & 30 & $n \mathrm{PrOH}$ & $100(90)$ & 21.7 \\
\hline 5 & 1 & 30 & $n \mathrm{BuOH}$ & $100(92)$ & 22.3 \\
\hline 6 & 0.5 & 30 & $\mathrm{MeOH}$ & 100 & 22.1 \\
\hline 7 & 0.5 & 30 & $\mathrm{EtOH}$ & $100(94)$ & 22.1 \\
\hline 8 & 0.5 & 30 & $n \mathrm{PrOH}$ & $100(86)$ & 21.8 \\
\hline \multirow[t]{2}{*}{9} & 0.5 & 30 & $n \mathrm{BuOH}$ & $100(89)$ & 21.2 \\
\hline & 0.1 & 30 & $\mathrm{MeOH}$ & 100 & 22.0 \\
\hline 11 & 0.1 & 30 & $\mathrm{EtOH}$ & $94(93)$ & 21.1 \\
\hline 12 & 0.1 & 30 & $n \mathrm{PrOH}$ & $45(37)$ & 10.6 \\
\hline 13 & 0.1 & 30 & $n \mathrm{BuOH}$ & 10 & 2.7 \\
\hline 14 & 0.5 & 0 & $\mathrm{MeOH}$ & 97 & 20.4 \\
\hline
\end{tabular}

Reaction conditions: $\mathrm{PhMe}_{2} \mathrm{SiH}(1.0 \mathrm{mmol})$, ruthenium complex, $1 \mathrm{~mL}$ of $\mathrm{ROH}$ for $10 \mathrm{~min}$. [a] Yields of silyl-ether determined by GC analysis using anisole as the internal standard. Isolated yields in parenthesis determined by ${ }^{1} \mathrm{H}$ NMR spectroscopic analysis using 1,3,5-trimethoxy benzene as external standard. [b] Volume of hydrogen gas collected using an inverted burette.

\section{Recycling properties and catalyst stability}

An important issue to consider for the pair silane/alcohol as a potential $\mathrm{LOHC}$ is that the catalyst should be recovered and reused at the end of the reaction. For that purpose, we evaluated the catalytic activity of a ruthenium complex immobilized on the surface of graphene by $\pi-\pi$ interactions using a pyrenyl tag attached to the NHC ligand (see structure in Table 1 and Figure 3). ${ }^{[4-50]}$ This supported catalyst has recently been developed by us and is very efficient in the dehydrogenation of alcohols and amines. ${ }^{[1,52]}$ The initial catalytic tests show that properties of the supported ruthenium catalyst in terms of stability and recyclability are very promising. The catalytic activity of the supported ruthenium catalyst in the dehydrogenative coupling of silanes with alcohols was tested and evaluated using the general conditions previously described (Table 3). The supported ruthenium catalyst is active for the coupling of a variety of silanes and alcohols. An initial experiment using only the reduced graphene oxide reveals that the presence of the ruthenium is necessary for the catalytic reaction. In all experiments, quantitative yields were obtained using a catalyst loading of $0.05 \mathrm{~mol} \%$ (Table 3). The catalytic activity is superior in the case of the heterogeneous system when comparing the molecular and supported ruthenium complexes. Most probably, the rGO material is stabilizing the catalytic active species. We have observed a similar effect when using molecular catalysts immobilized on the surface of graphene for different catalytic reactions. ${ }^{[48-52]}$

Table 2. Reaction scope

$$
\mathrm{R}_{4-\mathrm{n}} \mathrm{SiH}_{n}+\mathrm{nR} \mathrm{R}^{\prime} \mathrm{OH} \stackrel{[\mathrm{Ru}]}{\longrightarrow} \mathrm{R}_{4-\mathrm{n}} \mathrm{Si}\left(\mathrm{OR}^{\prime}\right)_{n}+\mathrm{nH}_{2}
$$

\begin{tabular}{cccccc}
\hline Entry & $\begin{array}{c}{[\mathrm{Ru}]} \\
(\mathrm{mol} \%)\end{array}$ & Silane & Alcohol & $\begin{array}{c}\text { Yield } \\
(\%)^{[\mathrm{a}]}\end{array}$ & $\mathrm{H}_{2}(\mathrm{~mL})^{[\mathrm{b}]}$ \\
\hline 1 & 1 & $\mathrm{Ph}_{3} \mathrm{SiH}$ & $\mathrm{MeOH}$ & 100 & 22.0
\end{tabular}

$\begin{array}{cccccc}1 & 1 & \mathrm{Ph}_{3} \mathrm{SiH} & \mathrm{MeOH} & 100 & 22.0 \\ 2 & 1 & \mathrm{Ph}_{3} \mathrm{SiH} & \mathrm{EtOH} & 78 & 16.3 \\ 3 & 1 & \mathrm{Ph}_{3} \mathrm{SiH} & n \mathrm{BuOH} & 44 & 8.7 \\ 4 & 1 & \mathrm{Ph}_{2} \mathrm{SiH}_{2} & \mathrm{EtOH} & 100(99) & 44.1\end{array}$

\begin{tabular}{c|ccccc}
4 & 1 & $\mathrm{Ph}_{2} \mathrm{SiH}_{2}$ & $\mathrm{EtOH}$ & $100(99)$ & 44.1 \\
5 & 1 & $\mathrm{Ph}_{2} \mathrm{SiH}_{2}$ & $n \mathrm{BuOH}$ & $100(94)$ & 43.8 \\
6 & 0.1 & $\mathrm{Ph}_{2} \mathrm{SiH}_{2}$ & $\mathrm{EtOH}$ & 55 & 24.6 \\
7 & 0.15 & $\mathrm{Ph}_{2} \mathrm{SiH}_{2}$ & $\mathrm{EtOH}$ & 70 & 31.0
\end{tabular}

\begin{tabular}{cccccc}
7 & 0.15 & $\mathrm{Ph}_{2} \mathrm{SiH}_{2}$ & $\mathrm{EtOH}$ & 70 & 31.0 \\
8 & 0.2 & $\mathrm{Ph}_{2} \mathrm{SiH}_{2}$ & $\mathrm{EtOH}$ & 84 & 36.6 \\
9 & 0.3 & $\mathrm{Ph}_{2} \mathrm{SiH}_{2}$ & $\mathrm{EtOH}$ & 100 & 44.5 \\
10 & 0.15 & $\mathrm{Ph}_{2} \mathrm{SiH}_{2}$ & $\mathrm{MeOH}$ & 87 & 37.0 \\
11 & 0.2 & $\mathrm{Ph}_{2} \mathrm{SiH}_{2}$ & $\mathrm{MeOH}$ & 100 & 43.9 \\
12 & 0.5 & $\mathrm{Ph}_{2} \mathrm{SiH}_{2}$ & $n \mathrm{BuOH}$ & $100(95)$ & 44.2 \\
13 & 0.3 & $\mathrm{Ph}_{2} \mathrm{SiH}_{2}$ & $n \mathrm{BuOH}$ & 54 & 23.2 \\
14 & 0.2 & $\mathrm{Ph}_{2} \mathrm{SiH}_{2}$ & $n \mathrm{BuOH}$ & 32 & 15.2 \\
15 & 0.3 & $\mathrm{Ph}_{2} \mathrm{SiH}_{2}$ & $n \mathrm{PrOH}$ & 90 & 39.4 \\
$16^{c}$ & 0.05 & $\mathrm{PhSiH}_{3}$ & $\mathrm{MeOH}$ & 34 & 10.1 \\
$17^{c}$ & 0.1 & $\mathrm{PhSiH}_{3}$ & $\mathrm{MeOH}$ & 93 & 31.2 \\
$18^{c}$ & 0.5 & $\mathrm{PhSiH}_{3}$ & $\mathrm{MeOH}$ & 100 & 33.5 \\
$19^{c}$ & 0.1 & $\mathrm{PhSiH}_{3}$ & $n \mathrm{PrOH}$ & 92 & 30.9 \\
$20^{c}$ & 0.1 & $\mathrm{PhSiH}_{3}$ & $n \mathrm{BuOH}$ & 84 & 28.2 \\
21 & 0.5 & $\mathrm{PhMe}_{2} \mathrm{SiH}^{2}$ & $\mathrm{PhCH} 2 \mathrm{OH}$ & 100 & 22.2 \\
\hline
\end{tabular}

Reaction conditions: Silane $(1.0 \mathrm{mmol})$, ruthenium complex, $1 \mathrm{~mL}$ of $\mathrm{ROH}$ for $10 \mathrm{~min}$ at $30^{\circ} \mathrm{C}$. [a] Yields of silyl-ether determined by GC analysis using anisole as the internal standard. Isolated yields in parenthesis determined by ${ }^{1} \mathrm{H}$ NMR spectroscopic analysis using 1,3,5-trimethoxybenzene as 
external standard. [b] Volume of hydrogen gas collected using an inverted burette. [c] $\mathrm{PhSiH}_{3}(0.5 \mathrm{mmol})$.

The stability of the supported ruthenium catalysts was evaluated by recycling experiments using dimethyl phenyl silane as model substrate (Figure 3). The solid catalyst was separated by decantation after each run, washed thoroughly with $\mathrm{MeOH}$ and reused. The supported ruthenium catalyst was employed for ten runs without observing any decrease in activity.

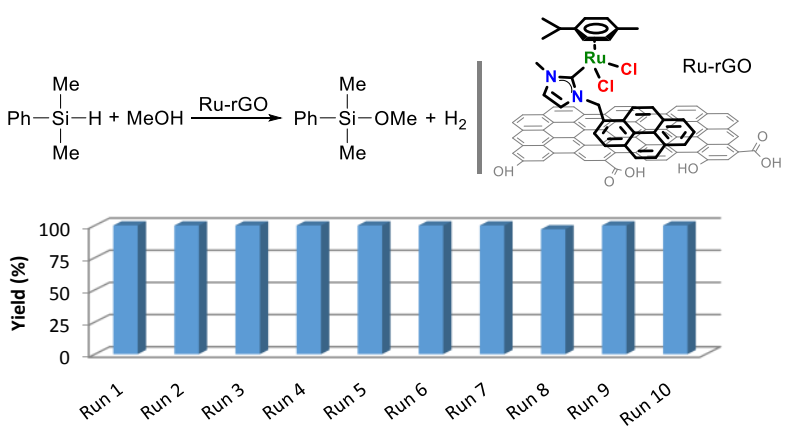

Figure 3. Recycling experiment using dimethyl phenyl silane as model substrate. Reaction conditions: Ru-rGO supported catalyst $0.5 \mathrm{Ru} \mathrm{mol} \%$. In each run $\mathrm{Ph}(\mathrm{Me})_{2} \mathrm{SiH}(1.0 \mathrm{mmol}), 3 \mathrm{~mL}$ of $\mathrm{MeOH}$ at $30{ }^{\circ} \mathrm{C}$ for $10 \mathrm{~min}$. Yields determined by GC using anisole as the standard.

The results in terms of stability and recyclability are excellent considering the low catalyst amount and that the reactions are carried out without special precautions. Deactivation processes are limited or avoided, in part, due to the low temperatures used to perform the reactions. The mild reaction conditions used do not affect the properties of the support. In order to evaluate any change in the reduced graphene oxide, the supported catalyst was analysed before and after the recycling studies by HRTEM microscopy and XPS. The results obtained by HRTEM (Figure 4) show that there is no change in morphology. The single layer nature of the sheets is preserved and the EDS elemental analysis shows the homogeneous distribution of ruthenium without the formation of nanoparticles. The XPS analysis confirms the observations obtained by microscopy (Figure S7-S9). The characteristic Ru3d peak at $281 \mathrm{eV}$ is observed in the molecular complex, the Ru-rGO and in the Ru-rGO material after the ten catalytic runs, indicating that the chemical environment of ruthenium is preserved. Similar results are observed for nitrogen and chlorine.

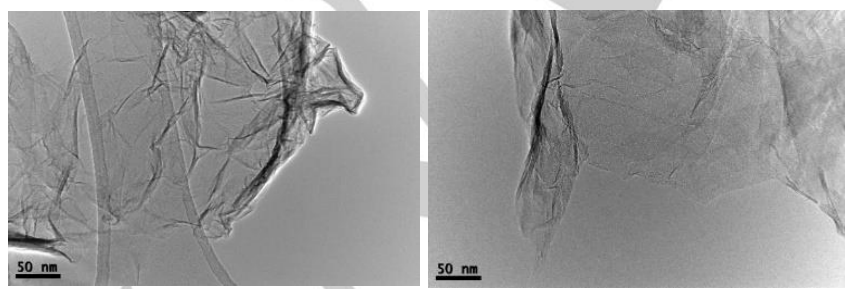

Figure 4. HRTEM images before (left) and after (right) ten catalytic cycles. The morphology of the reduced graphene oxide is preserved after the recycling experiments.
Table 3. Dehydrogenative coupling of silanes and alcohols using the ruthenium supported catalyst Ru-rGO.

\begin{tabular}{ccccc}
\hline Entry & Ru-rGO (mol \%) & Silane & Alcohol & Yield (\%) ${ }^{[a]}$ \\
\hline 1 & rGO & $\mathrm{PhMe}_{2} \mathrm{SiH}$ & $\mathrm{MeOH}$ & 0 \\
2 & 0.05 & $\mathrm{PhMe}_{2} \mathrm{SiH}$ & $\mathrm{MeOH}$ & 100 \\
3 & 0.05 & $\mathrm{PhMe}_{2} \mathrm{SiH}$ & $\mathrm{EtOH}$ & $100(93)$ \\
4 & 0.05 & $\mathrm{PhMe}_{2} \mathrm{SiH}$ & $n \mathrm{BuOH}$ & $95(90)$ \\
5 & 0.05 & $\mathrm{PhSiH}_{3}$ & $\mathrm{MeOH}$ & 90 \\
6 & 0.05 & $\mathrm{Ph}_{2} \mathrm{SiH}_{2}$ & $n \mathrm{BuOH}$ & $100(94)$ \\
\hline
\end{tabular}

Reaction conditions: Silane $(1.0 \mathrm{mmol}), \mathrm{Ru}-\mathrm{rGO}$ supported catalyst 0.05 $\mathrm{mol} \%$ based on $\mathrm{Ru}, 1 \mathrm{~mL}$ of $\mathrm{ROH}$ at $30^{\circ} \mathrm{C}$ for $10 \mathrm{~min}$. [a] Isolated yields of silyl ether in parenthesis determined by ${ }^{1} \mathrm{H}$ NMR spectroscopic analysis using 1,3,5-trimethoxybenzene as external standard

\section{Hydrogen storage capacity and regeneration}

The effective hydrogen storage capacity of the silane/alcohol pair is similar to other LOHCs (Figure 2). ${ }^{[24]}$ The maximum storage capacity is $5.0 \mathrm{wt} \%$ for the coupling of $\mathrm{SiH}_{4}$ with $\mathrm{MeOH}$, although not a useful system for practical applications due to the gaseous nature of silane. The structural versatility of hydrosilanes can increase the hydrogen capacity considerably. For instance, the efficient hydrogen storage capacity for the two liquid system $\mathrm{Ph}_{3} \mathrm{SiH} / \mathrm{MeOH}$ is only $0.7 \mathrm{wt} \%$. On the contrast, the use of a primary silane generates three moles of $\mathrm{H}_{2}$ and the effective hydrogen capacity for the reaction of $\mathrm{PhSiH}_{3} / 3 \mathrm{MeOH}$ is $3.0 \mathrm{wt} \%$. The effective hydrogen capacity of silanes is increased when using disilanes or methyldisilanes with the generation of six moles of $\mathrm{H}_{2}$ and still maintaining the liquid nature of reagents. ${ }^{[53]}$ Nevertheless, the use of the system $\mathrm{PhSiH}_{3} / 3 \mathrm{MeOH}$ is a good starting point for an initial evaluation of the potential application of the pair silane/alcohol as a practical LOHC ${ }^{[54]}$ In order to establish the stability of the ruthenium catalyst for real applications, a $10 \mathrm{~g}$ scale experiment was performed. The results show that all dimethylphenyl silane is converted in less than $15 \mathrm{~min}$ to the corresponding silyl ether in quantitative yield using a catalyst loading of $0.1 \mathrm{~mol} \%$ at $30^{\circ} \mathrm{C}$. The amount of silyl ether isolated by solvent evaporation was $12 \mathrm{~g}$ that corresponds to a $98 \%$ yield. The Ru complex is stable and exhibits high catalytic activity along with scalability. In view of these results, the dehydrogenative silane/alcohol coupling can be considered suitable for real applications.

A bottle-neck issue in the hydrogen storage using LOHCs is the regeneration process. The coupling of hydrosilanes and alcohols is chemoselective producing the silyl ether as the only reaction product. The formation of a single product facilitates the regeneration step. The dehydrogenation of other hydrogen carriers produce mixtures of products or even polymers that cause difficulties in the regeneration process. The regeneration of hydrosilanes from silyl ethers is performed by reduction using lithium aluminum tetrahydride $\left(\mathrm{LiAlH}_{4}\right)$ or other reducing agents. ${ }^{[55-60]}$ 


\section{Mechanistic considerations}

The proposed mechanism for the dehydrogenative coupling of alcohols and hydrosilanes catalysed by ruthenium-arene complexes is based on the ionic mechanism first proposed by Crabtree ${ }^{[61]}$ in the field of $\sigma$ bond coordination to metal centres. ${ }^{[62-}$ 65] Initial considerations, computational and experimental details have been included in the supporting information. The species involved are depicted in the catalytic cycle in Figure S10 and in the energy profile in Figure 6 . The ruthenium complexes $[\mathrm{Ru}(p-$ cym $\left.)(\mathrm{Cl})_{2}(\mathrm{NHC})\right]$ dissociate a $\mathrm{Cl}^{-}$anion generating the $[\mathrm{Ru}(p-$ cym $) \mathrm{Cl}(\mathrm{NHC})]^{+}$species, which is a highly electrophilic ruthenium cation. The equilibrium between these two species has previously been observed and depends on the solvent, the $\mathrm{pH}$ and the presence of nucleophiles. ${ }^{[51,52,66]}$ The ${ }^{1} \mathrm{H}$ NMR spectrum of the ruthenium complex $\left[\mathrm{Ru}(p\right.$-cym $\left.)(\mathrm{Cl})_{2}(\mathrm{NHC})\right]$ in $\mathrm{CDCl}_{3}$ displays one set of sharp signals, in contrast, the presence of different species was observed when the ${ }^{1} \mathrm{H}$ NMR spectrum was carried in $\mathrm{CD}_{3} \mathrm{OD}$. The process is reversible since the set of sharp signals was observed after the removal of $\mathrm{CD}_{3} \mathrm{OD}$ and the addition of $\mathrm{CDCl}_{3}$. This observation is an indication that $\mathrm{MeOH}$ promotes the equilibrium between neutral and cationic ruthenium species generating the electrophilic ruthenium active catalyst. In order to determine the catalyst resting state we performed a catalytic experiment using a $10 \mathrm{~mol} \%$ catalyst loading. The recovered species is the $\left[\mathrm{Ru}(p\right.$-cym $\left.)(\mathrm{Cl})_{2}(\mathrm{NHC})\right]$ suggesting that the catalyst resting state is out of the catalytic cycle (Scheme S5 and Figure S13). These observations are in agreement with the DFT calculations, which indicate that nucleophilic attack of the methanol is the rate-determining step (Figure 6). Further experimental evidences supporting the proposed mechanism is the dependence of dehydrogenative coupling on the nucleophilicity of alcohols (Table 1 , entries $10-13$ ), which suggests that alcohol attack to the coordinated silane is involved in the rate-determining step. The reactions between hydrosilanes and alcohols are faster when increasing the nucleophilic character of the alcohol. Similar catalytic results were observed when the metal complex $\left[\mathrm{CpRuPR}(\mathrm{MeCN})_{2}\right]^{+}$was used as catalyst. ${ }^{[67]}$. Another important consideration related to the proposed mechanism is the inherent reactivity between ruthenium-arene complexes and hydrosilanes described in the literature. ${ }^{[68,69]}$ Ruthenium-arene complexes react with hydrosilanes to give ruthenium hydrides and silyl chlorides using dichloromethane as solvent. When using alcohols, the formation of ruthenium hydrides is not observed due to silylation. Silyl chlorides react with alcohols to yield silyl ethers and hydrogen chloride that immediately protonates the ruthenium hydride, which subsequently releases hydrogen (Figure S12). Despite the catalytic dehydrogenative coupling of hydrosilanes with alcohols is a thermodynamically favourable process it requires a catalyst to proceed. The activation energy is very low in the presence of the ruthenium catalyst. The reaction profile at different temperatures in the range of -25 to $30^{\circ} \mathrm{C}$ shows that quantitative yields are obtained in short times ( $40 \mathrm{~s}$ ) and that the initial rates are very fast indicating that the activation energy is very low (Figure 5). These results are consistent with the theoretical calculations where the free energy profile shows a maximum energy transition state of only $8.0 \mathrm{kcal} / \mathrm{mol}$ (Figure 6 ).

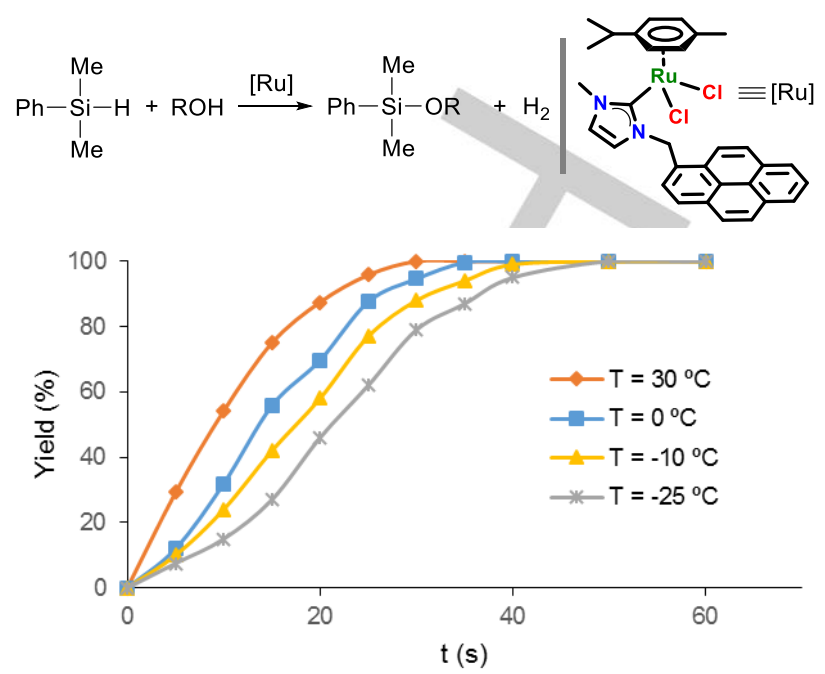

Figure 5. Reaction profile at different temperatures. Conditions: $1.0 \mathrm{mmol}$ of dimethyl phenyl silane, $1 \mathrm{~mL}$ of $\mathrm{MeOH}$ and $3 \mathrm{mg}(0.5 \mathrm{~mol} \%)$ of [Ru] catalyst. Yield corresponds to the amount of hydrogen collected using an inverted burette (Figure S1).

\section{Theoretical calculations}

Density Functional Theory (DFT) calculations provide a mechanistic overview of the catalytic reaction coupling based on the electrophilic activation of the silicon-hydrogen bond. ${ }^{[70-72]}$ The behaviour of the ruthenium complex towards dimethyl phenyl silane suggests that the catalytic process occurs via a $\left[\mathrm{Ru}\left(\eta^{6}-\right.\right.$ $\left.\left.\mathrm{C}_{6} \mathrm{H}_{6}\right)(\mathrm{NHC})(\mathrm{Cl})\left(\eta^{1}-\mathrm{H}-\mathrm{SiMe}_{2} \mathrm{Ph}\right)\right]^{+}$intermediate (I, Figure 6). Analysis of the $\sigma$ bond coordination in the ruthenium-silane complex reveals that: i) $\eta^{1}$ is the most favoured geometry, ii) no minima is observed for an $\eta^{2}-\mathrm{H}-\mathrm{SiR}_{3}$ coordination and iii) the oxidative addition is a highly disfavoured process. The origin of the $\eta^{1}-\mathrm{H}-\mathrm{SiR}_{3}$ coordination is based on steric factors (Section S7.2) as has been observed for bulky iridium complexes. ${ }^{[73]}$ The $\mathrm{Ru}-\mathrm{H}-\mathrm{SiR}_{3}$ interaction increases the electrophilic character at the silicon atom, which becomes susceptible of nucleophilic attack by the methanol substrate (III, Figure 6). Computational analysis suggests a back-attack of the alcohol to the coordinated $\mathrm{Si}-\mathrm{H}$ as in the case of a CpFe complex. ${ }^{[7]}$ The alcohol attack produces the neutral ruthenium hydride complex and the cation $\mathrm{R}_{3} \mathrm{Si}(\mathrm{H}) \mathrm{OMe}^{+}$(IV, Figure 6). Subsequently, the cation protonates the ruthenium hydride forming a dihydrogen complex that finally releases hydrogen gas (VI, Figure 6). As a summary, the ruthenium catalyst plays two main roles: (i) triggering the alcohol nucleophilic attack to the silane, and (ii) enabling the hydrogen evolution process from a metal-dihydrogen intermediate (Figure S10). 


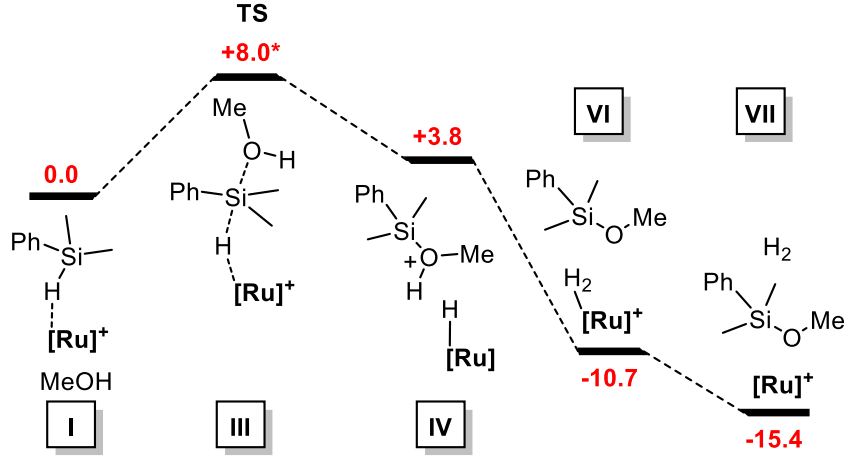

Figure 6. Abbreviated free energy profile for the dehydrogenative coupling of dimethyl phenyl silane and methanol catalysed by $\left[\mathrm{Ru}\left(\eta^{6}-\mathrm{C}_{6} \mathrm{H}_{6}\right) \mathrm{Cl}(\mathrm{NHC})\right]^{+}$in $\mathrm{Kcal} / \mathrm{mol}$ (Full profile in Figure S11).

\section{Conclusions}

In conclusion, we have shown that the dehydrogenative coupling of hydrosilanes with alcohols catalysed by $\left[\mathrm{Ru}(p-\mathrm{cym})(\mathrm{Cl})_{2}(\mathrm{NHC})\right]$ is an efficient system for the storage of hydrogen in the form of chemical bonds. We have demonstrated that primary, secondary and tertiary silanes couple with a variety of alcohols in good yields. Hydrogen is produced at high rates and low temperatures using low percentages of a ruthenium catalyst that controls the reaction kinetics. The ruthenium catalyst works without any additive and is robust enough to carry out the reactions without special precautions such as inert atmospheres or high temperatures. The immobilization of the ruthenium catalyst onto the surface of graphene allows the easy catalyst separation and recyclability. The results show that the catalyst activity increases when supported on reduced graphene oxide, most probably due to a stability enhancement produced by the graphene. The recycling properties show that the system can be reused for ten times without any decrease in activity. The hydrosilane/alcohol mixture is stable, non-toxic, easy to handle and versatile in terms of the availability of different types of silanes and alcohols. The effective hydrogen storage capacity is in the range of traditional LOHCs. The pair silane/alcohol is a potential liquid organic hydrogen carrier for energy storage in the near future.

\section{Acknowledgements}

The authors thank the financial support from MINECO (CTQ201569153-C2-1-R, CTQ2015-69153-C2-2-R and CTQ2015-67461P), Generalitat Valenciana (AICO/2015/039), Diputación General de Aragón (Grupo Consolidado E21) and Universitat Jaume I (P1.1B2015-09). D. V-E thanks the MINECO for the FPU grant (FPU15/03011). The authors are very grateful to the 'Serveis Centrals d'Instrumentació Científica (SCIC)' of the Universitat Jaume I and to the Instituto de Biocomputación y Física de Sistemas Complejos (BIFI) and the Centro de Supercomputación de Galicia (CESGA) for generous allocation of computational resources.
Keywords: Hydrogen storage $\cdot$ Liquid organic hydrogen carrier • On-demand hydrogen generation - Dehydrogenative coupling • Ruthenium catalysis• Hydrosilanes.

\section{References}

[1] U.S. Energy Information Agency, 2013, 312.

[2] N. Armaroli, V. Balzani, Energy for a Sustainable World: From the Oil Age to a Sun-Powered Future, Wiley-VCH, 2010.

[3] V. Blagojević, D. Minić, J. G. Novaković, D. Minić, Hydrog. Energy Challenges Perspect. 2012, 3-28.

[4] P. Jena, J. Phys. Chem. Lett. 2011, 2, 206-211.

[5] A. F. Dalebrook, W. Gan, M. Grasemann, S. Moret, G. Laurenczy, Chem. Commun. 2013, 49, 8735.

[6] K. Müller, W. Arlt, in Renew. Energy Econ. Emerg. Technol. Glob. Pract., Nova Science Publishers, Inc., 2013, pp. 45-60.

[7] A. Sartbaeva, V. L. Kuznetsov, S. A. Wells, P. P. Edwards, Energy Environ. Sci. 2008, 1, 79-85.

[8] G. W. Crabtree, M. S. Dresselhaus, M. V. Buchanan, Phys. Today 2004, 57, 39-44.

[9] G. Marbán, T. Valdés-Solís, Int. J. Hydrogen Energy 2007, 32, 1625-1637.

[10] M. Markiewicz, Y. Q. Zhang, A. Bosmann, N. Bruckner, J. Thoming, P. Wasserscheid, S. Stolte, Energy Environ. Sci. 2015, 8, 10351045.

[11] A. Züttel, Mater. Today 2003, 6, 24-33.

[12] A. Zuttel, A. Remhof, A. Borgschulte, O. Friedrichs, Philos. Trans. R. Soc. A Math. Phys. Eng. Sci. 2010, 368, 3329-3342.

[13] R. H. Crabtree, Energy Environ. Sci. 2008, 1, 134-138.

[14] M. Yadav, Q. Xu, Energy Environ. Sci. 2012, 5, 9698-9725.

[15] T. He, Q. Pei, P. Chen, J. Energy Chem. 2015, 24, 587-594.

[16] N. Brückner, K. Obesser, A. Bösmann, D. Teichmann, W. Arlt, J. Dungs, P. Wasserscheid, ChemSusChem 2014, 7, 229-235.

[17] A. Shukla, S. Karmakar, R. B. Biniwale, Int. J. Hydrogen Energy 2012, 37, 3719-3726.

[18] H. Liu, J. Softw. 2008, 19, 1317-1327.

[19] W. S. Han, T. J. Kim, S. K. Kim, Y. Kim, Y. Kim, S. W. Nam, S. O. Kang, Int. J. Hydrogen Energy 2011, 36, 12305-12312.

[20] D. Mukherjee, R. R. Thompson, A. Ellern, A. D. Sadow, ACS Catal. 2011, 1, 698-702.

[21] M. Aliaga-Lavrijsen, M. Iglesias, A. Cebollada, K. Garcés, N. García, P. J. Sanz Miguel, F. J. Fernández-Alvarez, J. J. Pérez-Torrente, L. A. Oro, Organometallics 2015, 34, 2378-2385.

[22] E. A. Ison, R. A. Corbin, M. M. Abu-Omar, J. Am. Chem. Soc. 2005 127, 11938-11939.

[23] W. Sattler, G. Parkin, J. Am. Chem. Soc. 2012, 134, 17462-17465.

[24] Q.-L. Zhu, Q. Xu, Energy Environ. Sci. 2015, 8, 478-512.

[25] D. Teichmann, W. Arlt, P. Wasserscheid, R. Freymann, Energy Environ. Sci. 2011, 4, 2767-2773.

[26] F. Schüth, Chemie Ing. Tech. 2011, 83, 1984-1993.

[27] R. B. Biniwale, S. Rayalu, S. Devotta, M. Ichikawa, Int. J. Hydrogen Energy 2008, 33, 360-365.

[28] N. Kariya, A. Fukuoka, M. Ichikawa, Appl. Catal. A Gen. 2002, 233, 91-102. 
G. P. Pez, A. R. Scott, A. C. Cooper, H. Cheng, W. F. Carl, A. H. Abdourazak, US Pat. ( 7351395 ), 2008.

[30] E. Clot, O. Eisenstein, R. H. Crabtree, Chem. Commun. 2007, 2231-2233.

[31] A. Boddien, D. Mellmann, F. Gartner, R. Jackstell, H. Junge, P. J. Dyson, G. Laurenczy, R. Ludwig, M. Beller, Science 2011, 333, 1733-1736.

[32] B. Loges, A. Boddien, F. Gärtner, H. Junge, M. Beller, Top. Catal. 2010, 53, 902-914.

[33] F. Joó, ChemSusChem 2008, 1, 805-808.

[34] C. Fellay, P. Dyson, G. Laurenczy, Angew. Chem. Int. Ed. 2008, 47, 3966-3968.

[35] M. Grasemann, G. Laurenczy, Energy Environ. Sci. 2012, 5, 81718181.

[36] A. K. Singh, S. Singh, A. Kumar, Catal. Sci. Technol. 2016, 6, 1240.

[37] D. Mellmann, P. Sponholz, H. Junge, M. Beller, Chem. Soc. Rev. 2016, 45, 3954-3988.

[38] T. B. Marder, Angew. Chem. Int. Ed. 2007, 46, 8116-8118.

[39] C. W. Hamilton, R. T. Baker, A. Staubitz, I. Manners, Chem. Soc. Rev. 2009, 38, 279-293.

[40] F. H. Stephens, V. Pons, R. Tom Baker, Dalton Trans. 2007, 26132626.

[41] M. C. Denney, V. Pons, T. J. Hebden, D. M. Heinekey, K. I. Goldberg, J. Am. Chem. Soc. 2006, 128, 12048-12049.

[42] N. Blaquiere, S. Diallo-Garcia, S. I. Gorelsky, D. A. Black, K. Fagnou, J. Am. Chem. Soc. 2008, 130, 14034-14035.

[43] W.-W. Zhan, Q.-L. Zhu, Q. Xu, ACS Catal. 2016, 6, 6892-6905.

[44] A. D. Sutton, A. K. Burrell, D. A. Dixon, E. B. Garner, J. C. Gordon, T. Nakagawa, K. C. Ott, J. P. Robinson, M. Vasiliu, Science 2011, 331, 1426-1429.

[45] N. C. Smythe, J. C. Gordon, Eur. J. Inorg. Chem. 2010, 2010, 509521.

[46] A. Staubitz, A. P. M. Robertson, I. Manners, Chem. Rev. 2010, 110, 4079-4124.

[47] D. Wechsler, Y. Cui, D. Dean, B. Davis, P. G. Jessop, J. Am. Chem Soc. 2008, 130, 17195-17203.

[48] S. Sabater, J. A. Mata, E. Peris, ACS Catal. 2014, 4, 2038-2047.

[49] S. Sabater, J. A. Mata, E. Peris, Organometallics 2015, 34, 11861190.

[50] S. Sabater, J. A. Mata, in Non-Covalent Interact. Synth. Des. New
Compd., John Wiley \& Sons, Inc, Hoboken, NJ, 2016, pp. 313-326.

[51] D. Ventura-Espinosa, C. Vicent, M. Baya, J. A. Mata, Catal. Sci. Technol. 2016, 6, 8024-8035.

[52] D. Ventura-Espinosa, A. Marzá-Beltrán, J. A. Mata, Chem. Eur. J. 2016, 22, 17758-17766.

[53] J. M. Brunel, Int. J. Hydrogen Energy 2010, 35, 3401-3405.

[54] L. Schlapbach, A. Züttel, Nature 2001, 414, 353-358.

[55] V. N. Gevorgyan, L. M. Ignatovich, E. Lukevics, J. Organomet. Chem. 1985, 284, C31-C32.

[56] S. V. Kirpichenko, A. I. Albanov, J. Organomet. Chem. 2010, 695, 663-666.

[57] P. Gigler, W. Herrmann, F. Kühn, Synthesis 2010, 2010, 14311432.

[58] K. Tamao, T. Yamauchi, Y. Ito, Chem. Lett. 1987, 16, 171-174.

[59] J. M. Tour, J. A. John, E. B. Stephens, J. Organomet. Chem. 1992 , 429, 301-310.

[60] M. Jeon, J. Han, J. Park, ACS Catal. 2012, 2, 1539-1549.

[61] X. L. Luo, R. H. Crabtree, J. Am. Chem. Soc. 1989, 111, 25272535.

[62] G. J. Kubas, in Compr. Organomet. Chem. III, 2007, pp. 671-698.

[63] R. H. Crabtree, Angew. Chemie Int. Ed. English 1993, 32, 789-805.

[64] R. N. Perutz, S. Sabo-Etienne, Angew. Chem. Int. Ed. 2007, 46, 2578-2592.

[65] G. I. Nikonov, in Adv. Organomet. Chem., Elsevier, 2005, pp. 217309.

[66] P. Csabai, F. Joó, Organometallics 2004, 23, 5640-5643.

[67] D. V. Gutsulyak, S. F. Vyboishchikov, G. I. Nikonov, J. Am. Chem. Soc. 2010, 132, 5950-5951.

[68] B. Bagh, D. W. Stephan, Dalton Trans. 2014, 43, 15638-15645.

[69] B. Chatterjee, C. Gunanathan, Chem. Commun. 2014, 50, 888-890.

[70] M. C. Lipke, A. L. Liberman-Martin, T. D. Tilley, Angew. Chem. Int. Ed. 2017, 56, 2260-2294.

[71] M. Iglesias, P. J. Sanz Miguel, V. Polo, F. J. Fernández-Alvarez, J. J. Pérez-Torrente, L. A. Oro, Chem. Eur. J. 2013, 19, 17559-17566.

[72] S. Lachaize, S. Sabo-Etienne, Eur. J. Inorg. Chem. 2006, 2006, 2115-2127.

[73] J. Yang, P. S. White, C. K. Schauer, M. Brookhart, Angew. Chem. Int. Ed. 2008, 47, 4141-4143.

[74] M. Bühl, F. T. Mauschick, Organometallics 2003, 22, 1422-1431. 


\section{Entry for the Table of Contents}
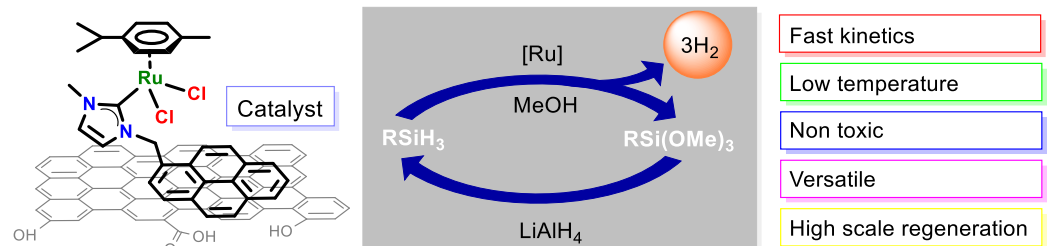

An effective supported ruthenium catalyst on the surface of rGO controls the hydrogen production from hydrosilanes. The hydrogen storage properties show the potential application of the silane/alcohol pair as an efficient liquid organic hydrogen carrier.
David Ventura-Espinosa, Alba CarreteroCerdán, Miguel Baya, Hermenegildo García* and Jose A. Mata*

Page No. - Page No.

Catalytic dehydrogenative coupling of hydrosilanes with alcohols for the production of hydrogen on-demand: Application of the pair silane/alcohol as liquid organic hydrogen carrier 